DOI https://doi.org/10.18551/rjoas.2016-10.14

\title{
EXPLORING ACTOR-NETWORK IN THE TICKET DISTRIBUTION CHANNEL: AN APPLICATION OF SOCIAL NETWORK ANALYSIS (A STUDY ON THE BUS TRANSPORTATION INDUSTRY IN EAST JAVA, INDONESIA)
}

\author{
Wilopo W. \\ Faculty of Administrative Science, University of Brawijaya, Indonesia \\ E-mail: maswilopo@gmail.com
}

\begin{abstract}
This study aims to investigate actor-network of marketing distribution channel specifically in the distribution channel for ticketing in the otobus industry. This industry is rarely being discussed as opposed to the airline industry. The purpose of this study is to provide actornetwork relationship that may determine the effectiveness of e-ticketing implementation for the otobus industry, which had been regulated by the Indonesian Ministry of Transportation. The social actor network analysis was employed due to its significance in providing a systematic information identifying, examining and supporting the process of knowledge transformation in the social network. The result indicated that informal actors had been in function as the intermediary of the ticket distribution. Understanding this important information is valuable for policy makers in the context of identifying the actor-network relationship of informal actors that may determine the effectiveness of policy innovation in the implementation of e-ticketing in the otobus industry.
\end{abstract}

\section{KEY WORDS}

Actor-network, ticket distribution channel, social network analysis, otobus industry.

The transportation industry plays an important role in Indonesian economy and it grows rapidly in terms of distribution (transport or delivery) of both goods and services. Although the economic growth in 2015 was not too high, the transportation industry showed a very bright business potential. In 2015 , Indonesia's economy decreased to only $4.8 \%$ from $5 \%$ per year over the last 5 years, since 2010. The slow but quite stable economic growth is seen as the main factor that drives the development of transortation industry. The other factor is the growing of middle class which reached 134 millions of people, $56.5 \%$ of the total Indonesian population in 2010 , and predicted to rise into 141 millions of people in 2030. The economic growth which is followed by the development of middle and upper economic classes is predicted to alter the expenditure structure of the whole 280 millions of Indonesian people in 2030.

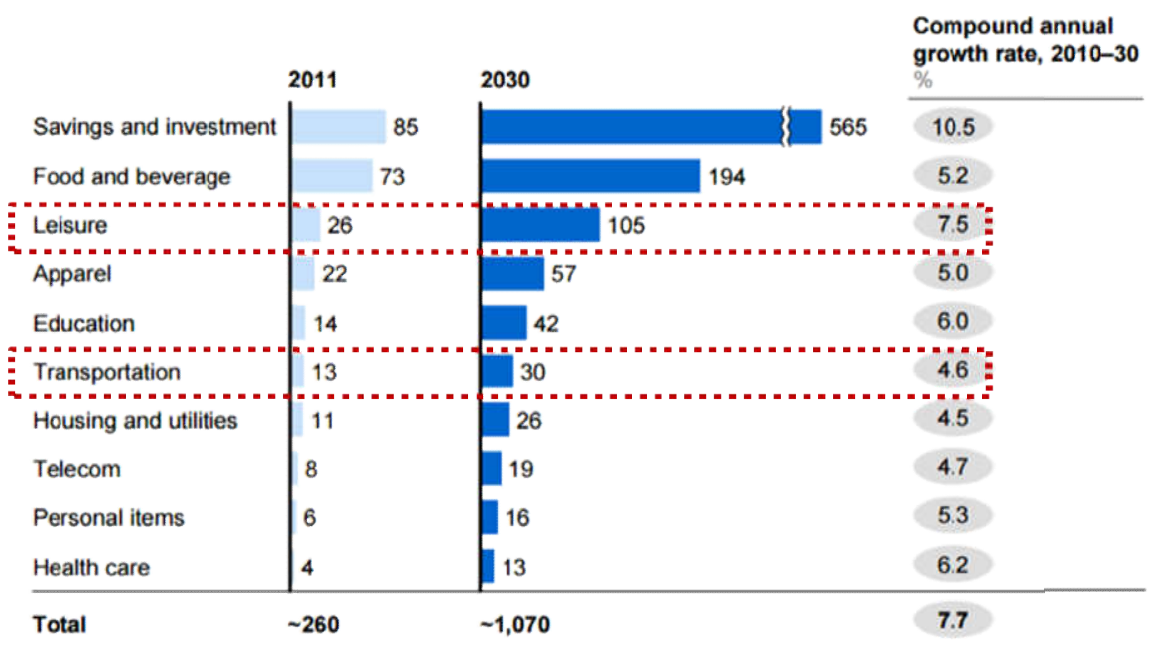

Figure 1 - Prediction of Indonesian People Consumption Structure in 2030. Source: McKinsey Global Institute, Unleashing Indonesia's Potential (2012) 
As predicted by McKinsey Global Institute, by 2030 the recreational expenditure will reach $\$ 105$ billions with the growth of $7.5 \%$ per year. For transportation spending, it is projected to reach $\$ 30$ billions with the growth of $4.6 \%$ per year. It can be concluded that the travels and transportation industry will continue to grow and develop. Among other means of transports, land transportation has the greatest role as compared to other due to its affordableness as well as the fact that it is the most widely mode being utilized by the public. In the Indonesian context of transportation, one important mode of transport is the bus lines, which are categorized into three types of trajectory based on the area or region in its path, namely: Inter-City in the Province (AKDP), Inter-City Inter-Province (AKAP), and Chartered Bus for tourism purpose. In the midst of intense competition, otobus companies sights an opportunity to develop the transportation business through expansion of e-ticketing market of Inter-City Inter-Province (AKAP). However, to implement e-ticketing in the bus transportation industry, it is important to understand the existing ticket sales distribution, find factors that can encourage the implementation of ticket digitization in that industry, and find the right proposition can be offered to Inter-City Inter-Province (AKAP) bus service. The prospects for bus lines services in Indonesia still have a potential, especially in East Java. This is due to the mobilization of road transport passengers, which is quite dense. Following a recent study in the context of land transport in Indonesia (Wilopo et al., 2016), it was reviewed that research with regard to the context of behavioural aspects on public transport in Indonesia (i.e. Joewono \& Kubota, 2007; Sumaedi et al., 2012; Hussein \& Hapsari, 2015; Sumaedi \& Medi Yarmen, 2015; Sumaedi et al., 2016), were mainly still focusing more on the perceptions of the users rather than exploring the relationships of actors that emerges in the context of land transportation. Furthermore, taking the context of marketing distribution channel as well as identifying actor-network relationships of the otobus industry, the social network analysis is undertaken in this study in order to provide a fruitful insight on the existence of actor-network which are pivotal in the marketing distribution.

As reviewed by Webster and Morrison (2004), the domain of marketing research network theories have been utilized to capture relationships among networks preceeding to behavioural pattern that include topic such as word-of- mouth (WOM) communication (i.e. Duhan, Johnson, Wilcox and Harrell, 1997; Goldenberg, Libai and Muller, 2001), relationship marketing (i.e Brodie, Coviello, Brookes and Little, 1997; Mattsson, 1997) as well as diffusion and adoption of new products and services (i.e Midgley, Morrison and Roberts, 1992; Morrison, Roberts and Midgley, 2000; Rogers, 1995). As the usefulness of regarding the network approach in marketing research is inevitable, this approach has been extended to focus on complex relationship involving network centrality in the flow of consumer influence (Lee et al., 2010) and even in the context of marketing tourism to reveal communication characteristics (Luo \& Zhong, 2015). Thus, this study contributes to the context of marketing distribution channel for in few avenues: (1) the nature of focus in the land transport industry, an area that is very rare being discussed in Indonesia; (2) the method being utilized to capture actor-network relationship; and (3) potential strategies in the implementation of ticketing distribution in the otobus industry.

\section{LITERATURE REVIEW}

Marketing channel system is a group of specific marketing channels used by a company where a decision on this system is regarded as one of the most important decisions taken by the management. Further, it is a method whereby businesses distribute their products or services to the customers and industries (Keegan \& Green, 2003). The selection of the distribution channel largely depends on the company's marketing strategy by taking into account segmentation, targeting and positioning. In managing the intermediary, the company must decide how much work need to be done to carry out the marketing strategies, namely: 1) push strategy, using the sales force, cash trade promotions, or other means to encourage intermediaries to bring, promote, and sell products to the end user; 2) pull strategy, using advertising, promotions, and other forms of communication to convince 
consumers to request product from intermediaries so as to encourage intermediaries for ordering these products.

According to Kotler (2009), distribution channel could be utilized as means of product mobilization. Furthermore, distribution channel can overcome the gap of time, place, and possession that separate goods and services from those who need or want them Also, Kotler (2009) contends that distribution channels of goods to customers can be classified based on the number of channels and the number of intermediary levels including: 1) zero-level channel, as distribution channel which consists of producers who sell directly to final consumers; 2) one-level channel, as distribution channel which has an intermediary for the sales; 3) two-level channel, as distribution channel which has two intermediaries for the sales; 4) three-level channel, as distribution channel which has three intermediary for the sales. Each channel has its strengths and weaknesses. The problem becomes more complex by the fact that now the majority of producers use mix channels. The reason is that every channel is needed to reach different segment and can deliver the right product at the lowest possible cost. There are few alternatives in determining the channels: 1) Based on the number of intermediaries, including exclusive distribution, selective distribution, intensive distribution; 2) Based on the conditions and responsibilities of channel members, including pricing policy, sale conditions, distributor territorial rights, shared services and responsibility (Kotler, 2009). In selecting distribution channels, the company must consider several factors affecting the distribution channels workability which in turn will affect the success and survival of the company.

As reviewed by Weitz and Jap (1995) that channel management research had recognized the necessity to understand relationships among people and firms that performs distribution functions that creates value for customers. Businesses had witnessed the development of marketing strategies by the utilization of hybrid channels which involves the ability to sell via digital channels (Friedman \& Furey, 1999). Moreover, organization's deployment of marketing and sales channel had triggered the awareness of businesses to transform their marketing strategy and challenge themselve to ensure the strategic fit of dynamic capabilities are balanced (Wilson \& Daniel, 2005). This means that business organizations are required to equalize their capability in terms of: (1) developing innovative channels that alters the way of which the business operates and how it interacts with the customers; and (2) maintaining the organization operating as as a single entity to create innovative channel combinations as well as to deliver consistent service (Wilson \& Daniel, 2005). Hence, the implementation of an approapriate distribution channel would allow businesses to easily service their customer in the competitive market (Pearce, 2008).

In the context of the present study, the demand of the customers in the otobus industry can be optimized with the use of technology through e-ticketing as an innovation that ensures enhanced level of servicing by business providers. The business and technological dynamics have trigerred the necessity to implement progressive approach that requires research development to yield innovative solutions in encountering to customer problems. Despite of the implementation of e-ticketing, technology used as a platform must always be updated in order to meet the demand of the customers. As argued by Crnojevac, et al (2010), when suppliers needs to increase the quality of their online service, they should constantly adjust their online marketing strategy to the requirements of the customers, centered on measurements of customer satisfaction and experience and on features of customer behavior. Thus, customers assess the quality of distribution, through the extent to which their needs are met through the distribution channel.

The tourism and travel industry had experienced dramatic change in the context of innovative solution through the development of e-ticketing as a result of the establishment of e-commerce. E-commerce by a simple definition is the extent to which internet and computer are used together with web browser to buy and sell product (McLeod, 2008). Furthermore, O'Brien and Marakas (2010) argue that e-commerce is changing the shape of competition, the speed of action, and the streamlining of interaction, and payment from customer to companies, and from companies to suppliers., E-commerce does not only associate with selling and buying activities online but the process of development, marketing, service and 
payment of products and services must be included holistically. E-ticketing is a product which from the basis of e-commerce specifically established in the context of the service industry utilized for tourism and travel purpose. Hence, the concept of e-commerce should be able to respond to that need by providing more customer focus and the ease of use to place an order beyond geographical boundaries (Bhatnagar et al., 2000; Yang et al., 2003).

E-ticketing is an approach to document selling process from the customers' travelling activity that ensures the practice of paperless revolution and considered as an efficient approach due to its practicability since travellers are able to book, pay for and print their etickets online from any point in the world. (Kruelle et al., 2006). Paper tickets are being progressively substituted for electronic tickets, reducing paper costs and making all the process more dynamic (Mut-Puigserver et al., 2012). Further, it is a means commerce, purchasing and selling activities of numerous services particularly in the travel industry via online media and thus, it is a way of which the tourism and travel industries facilitates their consumers to sufficiently access transactions online. The revolutionary of the development of e-ticketing had brought significant change in the ways of which people utilizes transactions as well as advantages that businesses in the travel and tourism industry has. The uniqueness and advantages of ticketing revolution can expand due to the utilization of multiple-platform either through websites or mobile phones. Several advantages could be determined through the use mobile applications as mentioned by Mut-Puigserver et al (2012), such as: (1) Customers are able to book everywhere, even without a printer; (2) Tickets can be bought and used immediately; (3) Easier and faster communication between the customers and the company; and (4) Company saves resources and speeds up the management process. Nonetheless the use of e-ticketing from a conventional basis does not instantly fulfill the needs of the customers (Crnojevac et al., 2010). For instance, ticketing distribution channel for land transport should assess types of features as well as behavioural pattern of customers to comply with the customers' needs.

\section{RESEARCH METHODOLOGY}

In conducting this research, a social network analysis that utilizes a qualitative approach was used. The research approach has been proven suitable to be used on nonscience or outside the field of science social phenomena. Data collection methods used was observation, interview, and documentation. Data analysis technique employed was Social Network Analysis, as a sociological paradigm for analyzing structural patterns of social relationships (i.e, Scott, 1991; Wasserman and Faust, 1994; Wellman \& Berkowitz, 1988). Social network analysis provides a systematic method to identify, examine and support the process of knowledge transformation in the social network (Müller-Prothmann, 2006). A social network analysis examines the structure of social relationships within a group to uncover the formal relationships between people. In consultation arrangement, this relationship is often in the form of communication, awareness, trust, and decision-making. Social Network Analysis (SNA) has become a growing trend in the trying to answer marketing phenomenon. Further, social network analysis (SNA) is a method used to achieve the results of analysis on almost all groups of interactions. Different sizes are determined to analyze the network cohesion, density and dimensions, and to analyze individually the important actor which has influence on the social networks (Wasserman and Faust, 1994).

In general, SNA leads to a process of social network analysis with regard to the structure and patterns of interaction attributes in it. At its core, the focus is on the interaction between the SNA attributes in it. Therefore, this research investigated the works of the attributes only because SNA discussed more about the relationship between actors rather than attributes of the actor. Actor is a term called as social entities, while ties are social relationships. Thus, the term each other create a social network. Gretzel (2001) noted that there are four important principles underlying the SNA perspective: 1) Actor, 2) Ties, 3) Network structure, 4) Social, economy, political, and other structures. Furthermore, the social network analysis might be able to provide fruitful insight as how network size, degree, density, reachability, connectivity distance as well as flow of information are determined 
(Dashgupta, 2013). In the context of marketing research, network theories have proven to be essential in determining the structure and functions of both; business to business and consumer market (Webster \& Morrison, 2004). Thus, this study utilized the use of social network approach in order to grasp the interaction among actors in ticketing distribution channel in the Otobus industry in East-Java, Indonesia.

\section{FINDINGS AND DISCUSSION}

Industrial Overview Based on Ticket Channel \& Distribution. Based on the survey conducted in 10 cities in East Java, it is known that there are 26 Inter-City Inter-Province (AKAP) otobus companies operating in East Java. Most companies focus on the middle and upper classes by providing Executive/VIP class services, while few of the rest operate in AC business and Super Executive class services. In selling the tickets, most of the companies used single and general agents in developing distribution channels of the ticket sales. The number of agents is determined based on the need to fulfill the quota of tickets to be sold, with the premise that «the more ticket agents they have, the easier the tickets can be sold».

In general, there are four (4) types of Inter-City Inter-Province (AKAP) bus ticket distribution. First, each ticket offices charge the ticket quota. The representative office provides each agent the quota of tickets to be sold. If the quota of an agent is discharged, the agent can ask additional tickets from other agents or representative offices. In this case, there is not any conflict in the possession of the total quota. Second, using request system, which is centralized. Agents are not targeted to sell tickets in a certain amount. To get a seat, agents are required to contact the representative office to inquire whether there is still an empty seat. Third, use ticket allocation system, which classifies agents into two types. Some agents have been allocated the tickets but some others are required to make request in order to get a ticket allocation. This system is commonly used to distinguish the exclusive agent and general agent. Fourth, because the companies do not have any agent/sales channel, the ticket sales system is combined with Inter-City in the Province (AKDP) system in which this system usually known with the term «fast».

To determine the scope of the research and to provide limitations on the conclusions, it is important to know the network. Researcher understanding on the size of the network is required to reveal the structure of social relationships existed at the given limited resources and capacities of each actor in building and maintaining the relationship. Using Social Network Analysis in general shows the results of data processing on Inter-City Inter-Province (AKAP) Bus industry policies as depicted in figure 1. The figure shows that the significant actors are company, general agent, single agent, terminal, and driver. This means that the major networks, originated from and lead to such actors affects Inter-City Inter-Province (AKAP) Bus industry.

Based on Act No. 22 of 2009 on Traffic and Transportation, the bus companies and Transportation Department should be the most important actors as the two organizations have the right to determine the governance of the Law No. 22/2009 on Road Traffic and Navy, as well as Inter-City Inter-Province (AKAP) Bus Industry in general. As can be seen, the five actors have an important function and role in AKAP Bus Industry. Therefore, the SNA visual analysis shows that almost all five actors have relationships. If there are some actors, which do not have relationships with all other actors, it is likely due to the absence of specific regulations that govern the five actors.

In the SNA analysis, there is a measure that can be used to analyze the significant actors called matrix analysis. The matrix analysis has three values, namely: (1) centrality, (2) density, and (3) eigenvector, which indicate significant levels of actors in the network. In terms of centrality measurement, in the SNA analysis, there are three sizes that can provide information about the role of the actor in the SNA network. The three-centrality measurements are (1) degree centrality, (2) closeness centrality and (3) betweenness centrality. 


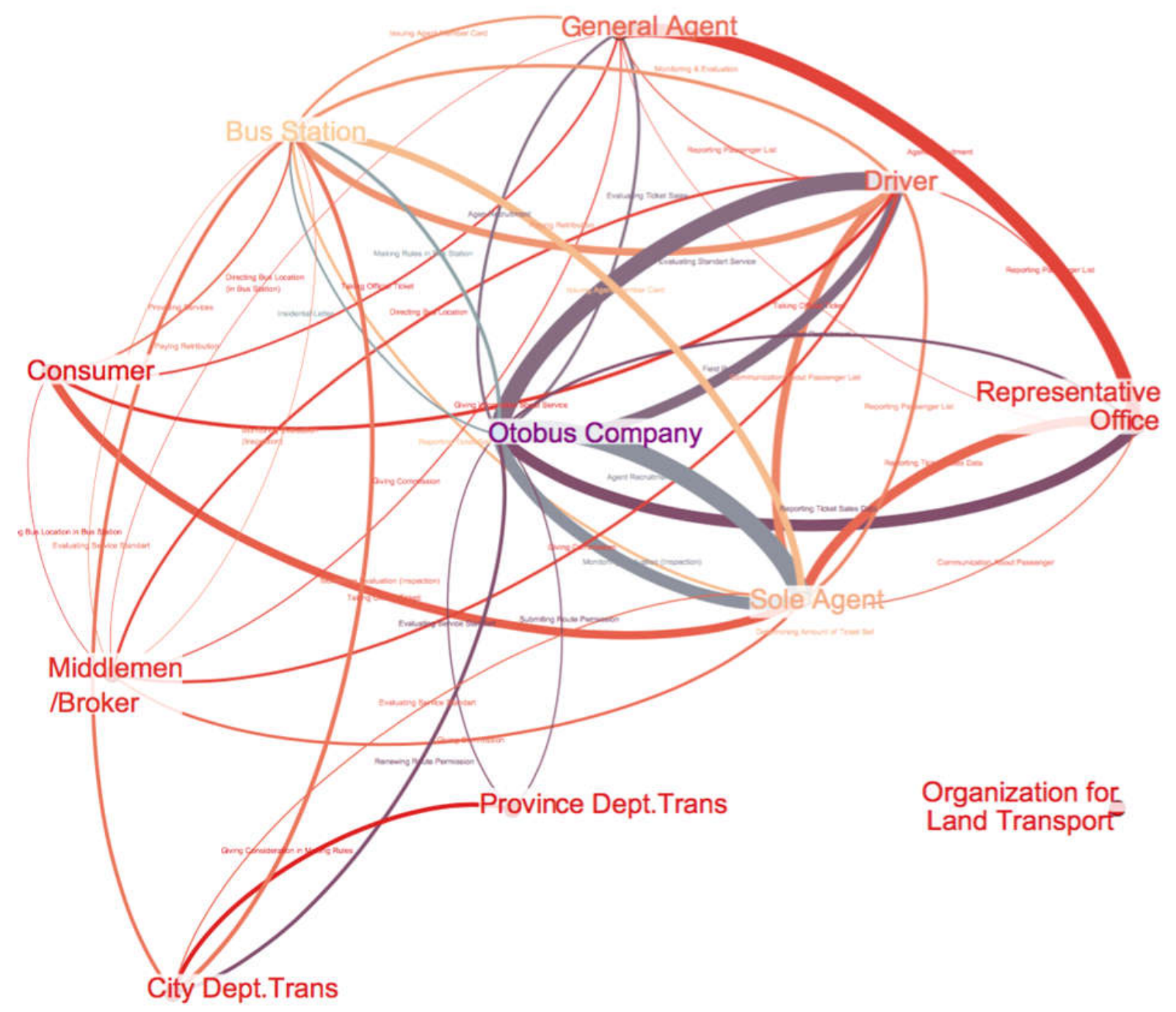

Restaurant:

Ministry of Transportation :

Figure 2 - Social Network Analysis Visualisation of AKAP Bus Industry in general

Tabel 2 Analysis of Degree and Centrality

\begin{tabular}{|c|l|c|c|c|c|c|}
\hline Id & \multicolumn{1}{|c|}{ Label } & In-Degree & Out-Degree & Degree & $\begin{array}{c}\text { Closeness } \\
\text { Centrality }\end{array}$ & $\begin{array}{c}\text { Betweenness } \\
\text { Centrality }\end{array}$ \\
\hline 1 & Ministry of transport & 0 & 0 & 0 & 0 & 0 \\
\hline 2 & Provincial Transport Dept & 2 & 1 & 3 & 0.473684211 & 0.002525253 \\
\hline 3 & City/Municipal Transport Dept & 2 & 3 & 5 & 0.6 & 0.005681818 \\
\hline 4 & Org. Land Transport (Organda) & 0 & 0 & 0 & 0 & 0 \\
\hline 5 & Terminal & 5 & 7 & 12 & 0.818181818 & 0.055808081 \\
\hline 6 & Otobus Company & 6 & 7 & 13 & 0.818181818 & 0.145454545 \\
\hline 7 & Headquarters & 6 & 3 & 7 & 0.6 & 0.00530303 \\
\hline 8 & Sole Agent & 5 & 7 & 13 & 0.75 & 0.046085859 \\
\hline 9 & General Agent & 4 & 4 & 9 & 0.642857143 & 0.025252525 \\
\hline 10 & Middlemen/broker & 4 & 7 & 8 & 0.6 & 0.009090909 \\
\hline 11 & Driver & 5 & 0 & 5 & 0 & 0.022979798 \\
\hline 12 & Consumer & 0 & 0 & 0 & 0 & 0 \\
\hline 13 & Restaurant & & & & 0.818181818 & 0 \\
\hline
\end{tabular}


In Degree. In degree is a measure of the degree centrality used to indicate that the actor became the most widely accessed actor by another actor or actors who often holds the role as an object. In AKAP Bus Industry in general, there are some actors who have greater in degree value. The results of data analysis using SNA showed the actors with the greatest in degree value among the eight actors in AKAP Bus Industry.

Out Degree. Out degree is one measure of the degree centrality used to indicate the actor with the most widely access to another actor or most often bears the role as the subjects in the SNA network. At the policies associated with AKAP Bus Industry in general, there are some actors who have greater out degree value than the other actors; namely company, driver, single agent, and terminal.

Betweenness Centrality. Betweenness centrality is a measurement used to determine how big the role of the actor/node to be able to be a liaison of inter-nodes that make the inter-nodes are linked together in connectivity. Based on the results of data analysis using Social Network Analysis, it is known that the company is an actor/node, which has the highest value of betweenness centrality among other actors/nodes. The highest betweenness centrality value owned by the otobus companies make this actor as a facilitator and organizer which is able to bridge the communication in AKAP Bus Industry in general in accordance with the primary function of enrichment through social network analysis (Marsden, 2002, D'Andrea, et al., 2010).

Closeness Centrality. Closeness centrality is also used to measure how much information can be transmitted from one node to another node. Closeness centrality value can be used to measure the proximity of an actor with other actors. The closer an actor with other actors, the easier an actor get information from other actors. The value of closeness centrality resulted is associated with AKAP Bus Industry in general. Otobus Company, terminal, and driver are actors who have the highest closeness centrality value. Then, they are followed by single agent, broker, and city transportation agency.

Eigenvector Centrality. Eigenvector centrality is the measurements used to find the most central actor in the SNA network. Through eigenvector centrality, the general distance between actors in a network pattern will be known. Actor with the highest value of eigenvector centrality became an actor, which has the most important role, as through eigenvector centrality value, the most popular actor that has the highest number of relationships with other actors in the network will be known. Based on the results of data analysis using Social Network Analysis, it is indicated that Otobus Company and driver has the highest eigenvector centrality value. Therefore, the company and driver became the most important actors in the network of AKAP Bus Industry in general.

Visualizing Social Network Analysis Distribution of AKAP Bus Ticket Sales. The results of data analysis on the policy of AKAP Bus Ticket Sales Distribution using Social Network Analysis are shown in the figure 2 below. The figure shows that the significant actors are otobus company, representative office, single agent, general agent, consumer, and driver. This means that AKAP Bus Ticket Sales Distribution is highly influenced by the networks which are originated from and lead to such actors.

Centrality is the nature of a social structure. Social centrality in a social network is arising from a relationship owned by a point to another point. Centrality analysis in a social network can provide insights about the role of an individual in the environment. Centrality can be divided into three categories: degree centrality, closeness centrality and betweenness centrality.

At AKAP Bus Ticket Sales Distribution policies, there are some actors who have greater out degree value than the other actors. They are single agent and driver. Single agent and driver at policies of AKAP Bus Industry in general became the most important actors in terms of accessing other actors. As mentioned earlier, single agent and driver has an out degree value greater than other actors. Their position as the most accesed actors by other actors make single Agent and driver as the most important actors in the policies associated with AKAP Bus Ticket Sales Distribution. The next highest out degree values is gained by the otobus company which has a relationship with company and single agent. 


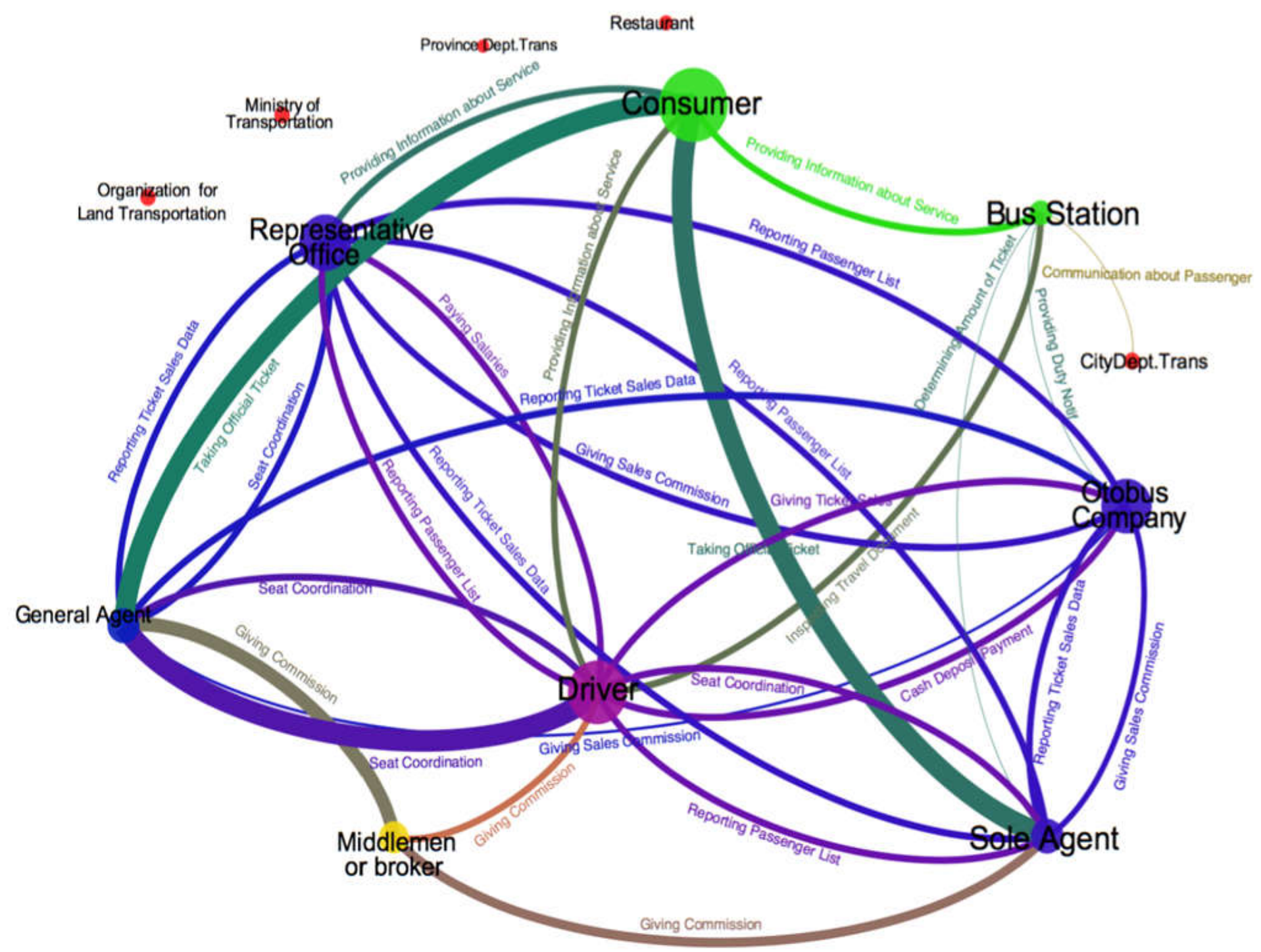

Figure 3 - Visualizing Social Network Analysis of AKAP Bus Ticket Sales Distribution 
Table 2 - Matrix Analysis of AKAP Bus Ticket Sales Distribution

\begin{tabular}{|c|l|c|c|c|c|c|}
\hline Id & \multicolumn{1}{|c|}{ Label } & In-Degree & Out-Degree & Degree & $\begin{array}{c}\text { Closeness } \\
\text { Centrality }\end{array}$ & $\begin{array}{c}\text { Betweenness } \\
\text { Centrality }\end{array}$ \\
\hline 1 & Ministry of transport & 0 & 0 & 0 & 0.0 & 0.0 \\
\hline 2 & Provincial Transport Dept & 0 & 0 & 0 & 0.0 & 0.0 \\
\hline 3 & City/Municipal Transport Dept & 1 & 0 & 1 & 0.0 & 0.0 \\
\hline 4 & Org. Land Transport (Organda) & 0 & 0 & 0 & 0.0 & 0.0 \\
\hline 5 & Terminal & 1 & 3 & 4 & 0.615384 & 0.0397727 \\
\hline 6 & Otobus Company & 4 & 5 & 9 & 0.727272 & 0.0934343 \\
\hline 7 & Headquarters & 4 & 2 & 6 & 0.533333 & 0.0025252 \\
\hline 8 & Sole Agent & 3 & 6 & 9 & 0.666666 & 0.0044191 \\
\hline 9 & General Agent & 3 & 4 & 7 & 0.615384 & 0.0195707 \\
\hline 10 & Middlemen/broker & 3 & 0 & 3 & 0.0 & 0.0 \\
\hline 11 & Driver & 3 & 6 & 9 & 0.727272 & 0.0448232 \\
\hline 12 & Consumer & 0 & 0 & 4 & 0.0 & 0.0 \\
\hline 13 & Restaurant & 0 & 0 & 0.0 & 0.0 \\
\hline
\end{tabular}

Source: Processed Data, 2015.

Based on the results of data processing using Social Network Analysis, it is known that company is an actor/node, which has the highest betweenness centrality value. The high betweenness centrality value of the company makes the actor a facilitator which is able to bridge communication in AKAP Bus Ticket Sales Distribution. The company position as an organizer of AKAP Bus Ticket Sales Distribution make it as a facilitator which is able to bridge the communication in AKAP Bus Ticket Sales Distribution in accordance with its main function of enrichment through social network analysis (Marsden, 2002, D'Andrea et al., 2010).

Closeness centrality is used to measure the average distance between an actor /node with other actors/nodes in the relationship. Closeness centrality is also used to measure how much information can be transmitted from one node to another node. Closeness centrality value can describe the measure of proximity of an actor with other actors. Results of data analysis of AKAP Bus Ticket Sales Distribution showed that Otobus Company and driver are the actors who have the highest closeness centrality value followed by sin leAgents, general Agents, and Terminal.

The actor who has the highest eigenvector centrality value is an actor who has the most important role. It is because through the measurement of eigenvector centrality the most popular actor who has the highest relationship with the other actors in the network will be known. Eigenvector centrality in general will produce list of actors with the highest value that is almost equal to the degree centrality (Marsden, 2002). This similarity happens because eigenvector centrality is a recursive version of the degree centrality. The results of data analysis using the Social Network Analysis indicate that in AKAP Bus Ticket Sales Distribution, otobus company, single Agent, and driver have the highest eigenvector centrality value. Through eigenvector centrality highest value, it means that otobus company, single Agent, and driver are the most important actors in AKAP Bus Ticket Sales distribution network.

\section{CONCLUSION}

In the research on Land Transportation Industry employed Actor Network Analysis which in this case has a specific locus and focus on the network of land transport modes ie buses, a series of activities related to the process of getting information on general picture of land transportation business have been done.

In the governance of the ticket distribution, there are several variations of systems used by the Otobus Company (PO); 1) direct governance by the Otobus Company (PO), where the ticket distribution channels to consumers are directly managed by the Otobus Company (PO). Mechanisms conducted by the Otobus Company (PO) are directly implemented by the Otobus Company (PO) on the relatively short routes. Furthermore, the monitoring functions 
of governance systems made directly by the Otobus Company (PO) using several methods such as (a) calculating the number of tickets sold in a day-time bus operation at the Otobus Company (PO) which apply e-deposit; or (b) the enactment of premium system between bus crew with the the Otobus Company (PO) management, for the company which bases its calculations on the total gross income; 2) Company Governance which involves a representative office in certain area (City/County). In the management of ticket distribution system, which involves a representative office, head office management gives authority to the representative office to perform the functions of marketing and sales and the representative office will report to the head office over an interval/period of time. In this case, the representative office runs marketing functions imposed by head office management. This kind of ticket distribution system is usually used by bus companies which provide medium and long trajectory service or have point-to-point journey from origin to final destinations; 3 ) distribution of tickets which involves head offices, representatives offices, and agencies. In this ticket distribution system, an agency is involved in distributing tickets through the sales mechanism. The existence of the agents in this distribution system is a strategy adopted by the representative offices to expand ticket distribution channel; 4) Ticket sales distribution which involves unofficial channel such as intermediaries or brokers. This indirect system involves intermediaries in the distribution channel of the tickets where the intermediary is actually not an actor officially designated by the company.

\section{REFERENCES}

1. Bhatnagar, A., Misra, S. and Rao, H.R. 2000. On risk, convenience, and Internet shopping behavior. Communications of the ACM, 43 (11), pp.98-105.

2. Crnojevac, H.I., Gugić, J., and Karlovčan, S. 2010. eTourism: A comparison of online and offline bookings and the importance of hotel attributes. Journal of Information and Organizational Sciences, 34 (1), 41-54.

3. DasGupta, B. and Desai, D. 2013. On the complexity of Newman $\square$ s community finding approach for biological and social networks. Journal of Computer and System Sciences, 79 (1), pp.50-67.

4. D'Andrea, A., Ferri, F., and Grifoni, P. 2010. An Overview of Methods for Virtual Social Networks Analysis. In A. Abraham, E.A. Hassanien \& V. Snášel, eds. Computational Social Network Analysis, Springer, London.

5. Friedman, L.G. and Furey, T.R. 1999. The Channel Advantage: Going to Market with Multiple Sales Channels to Reach More Customers, Sell More Products, Make More Profit. Routledge.

6. Gretzel, U. 2001. Social Network Analysis: Introduction and Resources. Retrieved form http://Irs.ed.uiuc.edu/TSE-portal/analysis/social-network-analysis/ accessed in January 7, 2016.

7. Keegan, W.J. and Green, M. 2003. Global Marketing. 3/e. ed.

8. Kotler, P., Keller, K., Brady, M., Goodman, M., and Hansen, T. 2009. Marketing Management. Pearson Education Ltd, England.

9. Lee, S.H.M., Cotte, J., and Noseworthy, T.J. 2010. The role of network centrality in the flow of consumer influence. Journal of Consumer Psychology, 20 (1), pp.66-77.

10. Luo, Q. and Zhong, D. 2015. Using social network analysis to explain communication characteristics of travel-related electronic word-of-mouth on social networking sites. Tourism Management, 46, pp.274-282.

11. Ng-Kruelle, G., Swatman, P.A., and Kruelle, O. 2006. E-ticketing Strategy and Implementation in an Open Access System: The Case of Deutsche Bahn. Information Technology and Tourism.

12. O'Brien, J. and Marakas, G.M., 2010. Introduction to Information Systems. McGrawHill/Irwin. New York.

13. Marsden, P. 2002. Egocentric and Sociocentric Measures of Network Centrality. Social Networks, 24 (4), pp 407-22. 
14. Müller Prothmann, Tobias. 2006. Leveraging Knowledge Communication for Innovation. Framework, Methods and Applications of Social Network Analysis in Research and Development. Frankfurt a. M. et al.: Peter Lang.

15. Mut Puigserver, M., Payeras Capellà, M.M., Ferrer Gomila, J.L., Vives Guasch, A., and Castellà Roca, J. 2012. A survey of electronic ticketing applied to transport. Computers \& Security, 31 (8), pp.925-939.

16. Oberman, R., Dobbs, R., Budiman, A., Thompson, F., and Rossé, M. 2012. The Archipelago Economy: Unleashing Indonesia's Potential. McKinsey Global Institute.

17. Pearce, D.G. 2008. A needs-functions model of tourism distribution. Annals of Tourism Research, 35 (1), pp.148-168.

18. Republic Indonesia. 2009. Undang-Undang No. 22 Tahun 2009 tentang Lalu Lintas dan Angkutan Jalan, Lembaran Negara RI Tahun 2009 (Law on Traffic and Road Transport).

19. Scott, J. 1988. Social network analysis. Sociology, 22 (1), pp.109-127.

20. Wasserman, S. and Faust, K. 1994. Social Network Analysis: Methods and Applications. Cambridge University Press, Cambridge, ENG and New York.

21. Webster, C.M. and Morrison, P.D. 2004. Network analysis in marketing. Australasian Marketing Journal (AMJ), 12 (2), pp.8-18.

22. Wellman, B. And Berkovitz, S. 1998. Social Structures: A Network Approach. Cambridge University Press, Cambridge and New York.

23. Weitz, B.A. and Jap, S.D. 1995. Relationship marketing and distribution channels. Journal of the academy of Marketing Science, 23b(4), pp.305-320.

24. Wilopo, Iqbal, M., and Sanjaya, A. 2016. TPB and employees' intention to support organizational change through the adoption of e-ticketing: A survey of employees of private bus lines in Malang- Indonesia. International Journal of Management and Administrative Sciences, 3 (10). pp. 107-121.

25. Wilson, H. and Daniel, E. 2007. The multi-channel challenge: A dynamic capability approach. Industrial Marketing Management, 36 (1), pp.10-20.

26. Yang, Z., Peterson, R.T., and Cai, S. 2003. Services quality dimensions of Internet retailing: An exploratory analysis. Journal of Services Marketing, 17 (7), pp.685-700. 